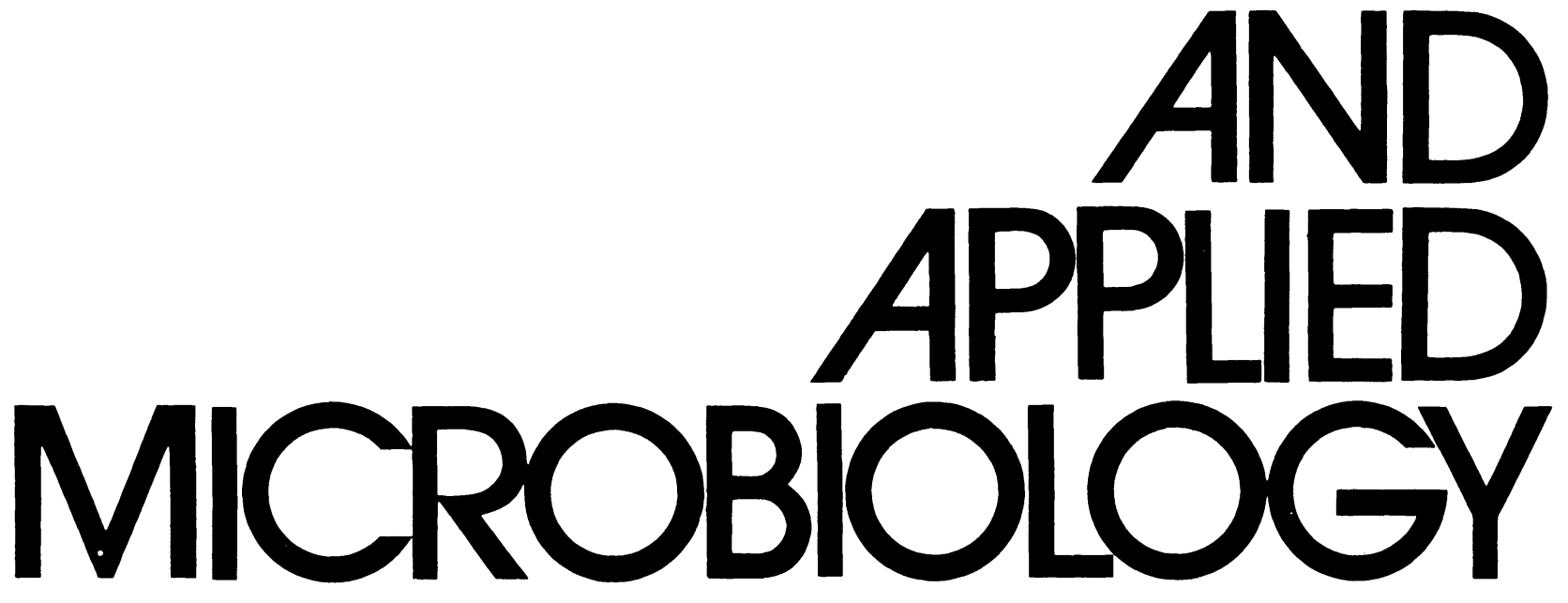

formerly Zentralblatt für Bakteriologie, Mikrobiologie und Hygiene

I. Abt. Originale C

Gropp et al. (1986)

Homologies of compo-

nents of DNA-dependent

RNA polymerases of

archaebacteria,

eukaryotes and eubact.

Gustav Fischer Verlag
Stuttgart - New York 



\title{
Homologies of Components of DNA-dependent RNA Polymerases of Archaebacteria, Eukaryotes and Eubacteria*
}

\author{
F. GROPP ${ }^{1}$, W. D. REITER ${ }^{1}$, A. SENTENAC ${ }^{2}$, W. ZILLIG ${ }^{1}$, R. SCHNABEL ${ }^{3}$, M. THOMM ${ }^{4}$, and K. O. \\ STETTER ${ }^{4}$ \\ 1 Max-Planck-Institut für Biochemie, D-8033 Martinsried, Federal Republic of Germany \\ 2 Centre d'Etudes Nucléaires de Saclay, F-91191 Gif-sur-Yvette Cedex, France \\ 3 Present address: Medical Research Council, Cambridge CB2 2QH, Great Britain \\ 4 Institut für Biochemie, Genetik und Mikrobiologie der Universität Regensburg, D-8400 Regensburg, Federal Republic of Germany
}

\begin{abstract}
Summary
Using an immunochemical approach homologies between single components of DNA-dependent RNA polymerases from eubacteria, archaebacteria and eukaryotes were investigated. The largest components of all RNA polymerases included in this study are homologous to one another indicating a monophyletic origin of these proteins.

Immunological crossreactions show that one of the large subunits present in the enzymes of sulfurdependent archaebacteria is split into two smaller components in methanogens and halophiles. One of these smaller components roughly corresponds to the second largest subunit of the three eukaryotic enzymes whereas the other one shares antigenic determinants with subunit $\beta$ of eubacterial RNA polymerases.

Semi-quantitative evaluation of the data suggests that the three nuclear RNA polymerases of eukaryotes have evolved from an ancestral enzyme of the type that is found in sulfur-dependent archaebacteria.
\end{abstract}

Key words: Archaebacteria - RNA polymerase - Immunological crossreaction - Phylogeny - Evolution

\section{Introduction}

Comparative cataloging of $T_{1}$-RNase generated fragments of 16S-rRNAs has led to the concept that all living organisms can be classified into one of three major groups: the "urkingdoms" of the eubacteria, the archaebacteria and the eukaryotes (Woese and Fox, 1977; Woese et al., 1978; Fox et al., 1977). Since then much additional evidence has been accumulated confirming the idea that there are two groups of prokaryotes that are no more related to one another than either of them is related to the eucyta (i. e. the nuclear plus the cytoplasmic compartment of the eukaryotes). This evidence includes comparison of different parts of the translation apparatus (Fox et al., 1982; Matheson and Yaguchi, 1982; Yaguchi et al., 1982; Gupta, 1984; Kessel and Klink, 1982; Cammarano et al., 1985), of the enzymes involved in replication (Prangishvilli and Zillig, 1984; Forterre et al., 1984; Nakayama et al., 1985; Klimczak et al., 1985) and transcription (Zillig

* Paper given at the EMBO Workshop on the Molecular Genetics of Archaebacteria, München-Martinsried, June 23 to 26, 1985 . et al., 1982; Schnabel et al., 1983; Huet et al., 1983; Prangishvilli et al., 1982), of cell wall composition (Kandler, 1982) and membrane structure (review by Langworthy et al., 1982).

In order to study phylogenetic relationships and evolution of different organisms it is desirable to compare cellular components that:

(1) are present in all organisms under investigation,

(2) have already been present very early in evolution, and

(3) are sufficiently complex that statistically significant data can be obtained.

These criteria are ideally met by some proteins and nucleic acids involved in transcription, translation and replication. Whereas ribosomal proteins and most DNA polymerases are too small or of too low complexity to be well suited for investigating phylogenetic relationships, the analysis of the large ribosomal RNAs and of RNA polymerases yields valuable information concerning phylogeny and evolution.

The comparison of the antibiotic responses as well as the component patterns and subunit homologies of RNA 
polymerases from organisms belonging to different phylogenetic groups:

(1) confirms that there is a deep division within the prokaryotes separating eubacteria and archaebacteria,

(2) is independent evidence that within the urkingdom of archaebacteria there are two major branches, one formed by the halophilic and methanogenic archaebacteria and the other formed by the thermophilic sulfur metabolizing archaebacteria, and

(3) suggests that the three eukaryotic nuclear RNA polymerases have evolved from an ancestral enzyme of the archaebacterial type.

\section{Properties of Different DNA-dependent RNA Polymerases}

\section{Eukaryotic nuclear RNA polymerases}

Within the nuclear compartment of eukaryotic cells three RNA polymerases are involved in the transcription of different "classes" of genes. Polymerase I (or A) is responsible for transcription of rDNA (with the exception of 5S-rRNA genes) whereas the formation of hnRNA is catalyzed by RNA polymerase II (or B). The genes for some small RNA species including 5S-rRNA and tRNAs are transcribed by RNA polymerase III (or C).

All eukaryotic nuclear RNA polymerases are insensitive to the antibiotics rifampicin and streptolydigin that strongly inhibit the RNA polymerases of eubacteria. A typical inhibitor of eukaryotic RNA polymerases is the mushroom poison $\alpha$-amanitin that blocks transcription by RNA polymerase II at very low concentrations. In most eukaryotes the activity of polymerase III is affected by high concentrations of this inhibitor whereas polymerase I is insensitive. Examples can be found, however, where the inhibition pattern is different. In yeast for instance RNA polymerase I is inhibited by $\alpha$-amanitin but polymerase III is not.

The component pattern of all three eukaryotic RNA polymerases is very complex. Analysis by SDS polyacrylamide gel electrophoresis shows the presence of 10 or more different polypeptide chains with molecular weights ranging from 10 kilodaltons to more than 200 kilodaltons. With the exception of polymerase III, where subunits of intermediate size are found, each eukaryotic RNA polymerase is composed of two very large subunits (molecular weight above 100 kilodaltons) and several smaller components (molecular weight below 50 kilodaltons). Usually, designations have been given to single components that include the type of enzyme as well as the molecular weight of the subunit. Thus the largest component of yeast RNA polymerase $I$ is referred to as $I_{190}$, the second largest as $I_{135}$ etc. Comparison of single subunits of RNA polymerases from different organisms is facilitated, however, when a somewhat different nomenclature is employed. We therefore decided to call the largest subunit of yeast RNA poly-
EUKARYOTES

Yeast
RNA Pol
I II

( (B) 135 ש2 150

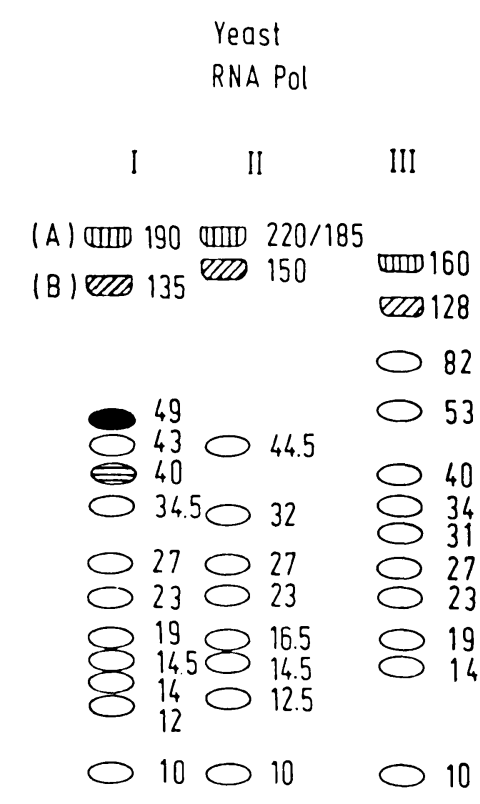

ARCHAEBACTERIA

EUBACTERIA

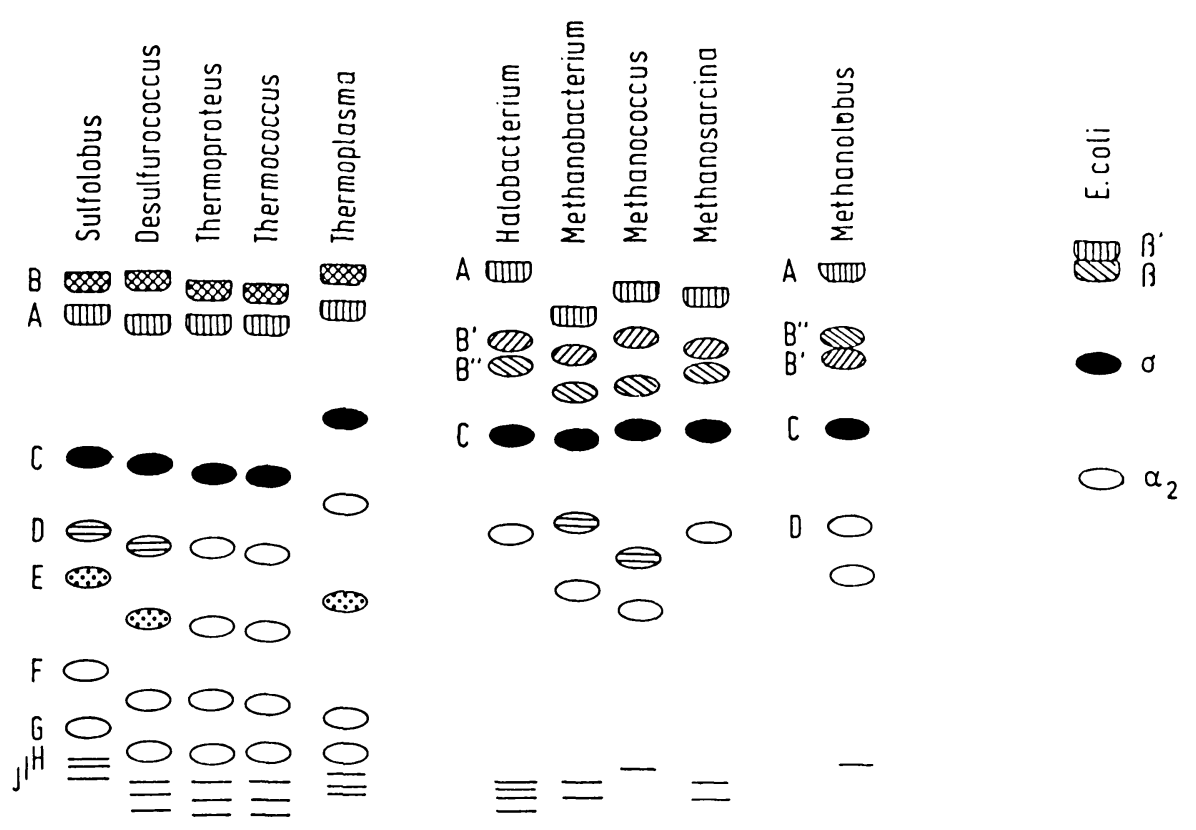

Fig. 1: Schematic drawing of the component patterns of DNA-dependent RNA polymerases of eukaryotes, archaebacteria and eubacteria obtained by separation of polypeptide chains by SDS polyacrylamide gel electrophoresis.

The numbers give the apparent molecular weights in kilodaltons of the components of the yeast enzymes. Capital letters are used for the designation of the components of archaebacterial RNA polymerases and of the two largest subunits of the yeast enzymes. Equal design of components from different RNA polymerases indicates homology. 
merases " $A$ " and the second largest subunit " $B$ " irrespective of the type of polymerase (I, II or III). All "A" subunits of eukaryotic RNA polymerase are homologous and the same is true for the "B" components (Huet et al., 1983 and data presented here). Some of the smaller components are identical in all three RNA polymerases and others are common to two of the three enzymes. Most of the components, however, are unique and can only be found in one of the RNA polymerases (for a detailed review see Paule, 1981).

\section{Eubacterial RNA polymerases}

In contrast to the situation found in eukaryotes all genes of eubacteria are transcribed by one RNA polymerase. The enzyme is strongly inhibited by the antibiotics rifampicin and streptolydigin but its activity is not affected by $\alpha$-amanitin.

As in the eukaryotic enzymes there are two large subunits (termed $\beta$ and $\beta$ ') but very small components are completely missing. Typically eubacterial enzymes contain two copies of a subunit of intermediate size $(\alpha)$ as well as an initiation factor termed $\sigma$ that is involved in promotor recognition (cf. Zillig et al., 1976; Burgess, 1976). This $\sigma-$ factor is a stoichiometric component of some eubacterial RNA polymerases (Herzfeld and Kiper, 1976). In most eubacteria, however, it is only temporarily associated with the enzyme.

\section{Archaebacterial RNA polymerases}

As in eubacteria only one RNA polymerase appears to be responsible for transcription of all genes in archaebacteria. Archaebacterial RNA polymerases are not inhibited by rifampicin, streptolydigin or $\alpha$-amanitin and no substance is known that specifically blocks RNA synthesis by the archaebacterial enzyme. Its activity is blocked, however, by such general inhibitors of transcription as heparin and actinomycin D. Two different types of RNA polymerases are observed corresponding to the two major branches of this urkingdom. The component pattern of the enzymes found in sulfur-dependent archaebacteria and Thermoplasma closely resembles that of the eukaryotic RNA polymerases (especially polymerase I and II). In halophilic and methanogenic archaebacteria a somewhat different subunit composition is observed. Typically there is one large subunit of a molecular weight greater than 100 kilodaltons and two components of about 60-90 kilodaltons. Analogous to the enzymes from sulfur-dependent archaebacteria (including Thermoplasma) and eukaryotes, several smaller polypeptide chains strictly copurify with the larger components. In the following, the term „sulfurdependent archaebacteria" is meant to include the thermoacidophilic genus Thermoplasma if not noted otherwise.

\section{Homologies Between Subunits of RNA Polymerases from Eubacteria, Eukaryotes and Archaebacteria}

RNA polymerases and antibodies used for investigation of homologies

Antibodies were directed against single components of the RNA polymerases from Sulfolobus acidocaldarius and Methanobacterium thermoautotrophicum (Schnabel et al., 1983), against the subunits of the Escherichia coli polymerase and against those of the three nuclear enzymes of Saccharomyces cerevisiae (A. Sentenac).

The yeast enzymes I and II (Bubler et al., 1980) were used for immunoblotting as representatives of eukaryotic RNA polymerases. Archaebacterial RNA polymerases were from Sulfolobus acidocaldarius (Zillig et al., 1979). Halobacterium halobium (Zillig et al., 1978; Madon and Zillig, 1983). Methanococcus thermolithotrophicus (Thomm and Stetter, 1985) and Methanolobus vulcanii (M. Thomm, unpublished). As a representative of a eubacterial RNA polymerase the enzyme from E. coli was used.

\section{The technique of immunoblotting}

The simplest way to detect homologies between different polypeptide chains is to look for common antigenic determinants.

The antibodies used in such studies must meet two demands:

(1) they must be polyclonal so that different antigenic determinants of a polypeptide chain are recognized;

(2) they must be directed against a denatured polypeptide chain (so-called "sequence-specific antibodies"); otherwise homolgies of sequences that are hidden in the interior of a native protein can be overlooked.

After separation of different polypeptide chains by SDS polyacrylamide gel electrophoresis, the resulting component pattern is blotted to nitrocellulose sheets and challenged with the antibody of interest. Bound antibody can be visualized by employing labelled protein A from $S$. aureus that is known to bind specifically to the $F_{c}$ part of immunoglobulins. A somewhat different approach uses a second antibody that is directed against the $F_{c}$ part of the first one. This second antibody is usually covalently linked to an enzyme capable of catalyzing a colour reaction (a peroxidase is used in most cases).

The most important disadvantage of the immunological approach is the fact that similar amino acid sequences do not necessarily result in common antigenic determinants. Thus it must be borne in mind that the absence of an immunological crossreaction does not necessarily mean that two proteins are completely unrelated on sequence level. Though direct comparison of protein sequences yields more information than the immunochemical method, the latter is simple to perform and results can be obtained with very little experimental effort. Nevertheless it is highly desirable to compare amino acid sequences of those proteins for which an immunological crossreaction has been demonstrated. 


\section{The " $A$ " components of DNA-dependent RNA polymerases}

Immunological crossreactions show the following components to be homologous:

- The largest subunit of the three eukaryotic nuclear RNA polymerases (i. e. the "A" subunits of these enzymes)

- The second largest subunit of the RNA polymerases from sulfur-dependent archaebacteria

- The largest subunit of the RNA polymerases from halophilic and methanogenic archaebacteria

- Subunit $\beta^{\prime}$ of eubacterial RNA polymerases

Those components of archaebacterial RNA polymerases that are homologous to the A subunits of the eukaryotic enzymes have also been given the designation " $\mathrm{A}$ ", though in the case of sulfur-dependent archaebacteria this subunit is not the largest one. For the homologies listed above the following evidence has been obtained:

(1) Antibodies raised against the largest subunit of the three eukaryotic RNA polymerases crossreact with component A of all archaebacterial enzymes (i.e. the largest component in the halophilic/methanogenic branch and the second largest one of sulfur-dependent archaebacteria). Typically this crossreaction is much stronger with the archaebacterial RNA polymerase than it is with the corresponding subunits of the two other eukaryotic enzymes. Antibodies directed against the A subunit of yeast RNA polymerase III for instance give a strong signal with the

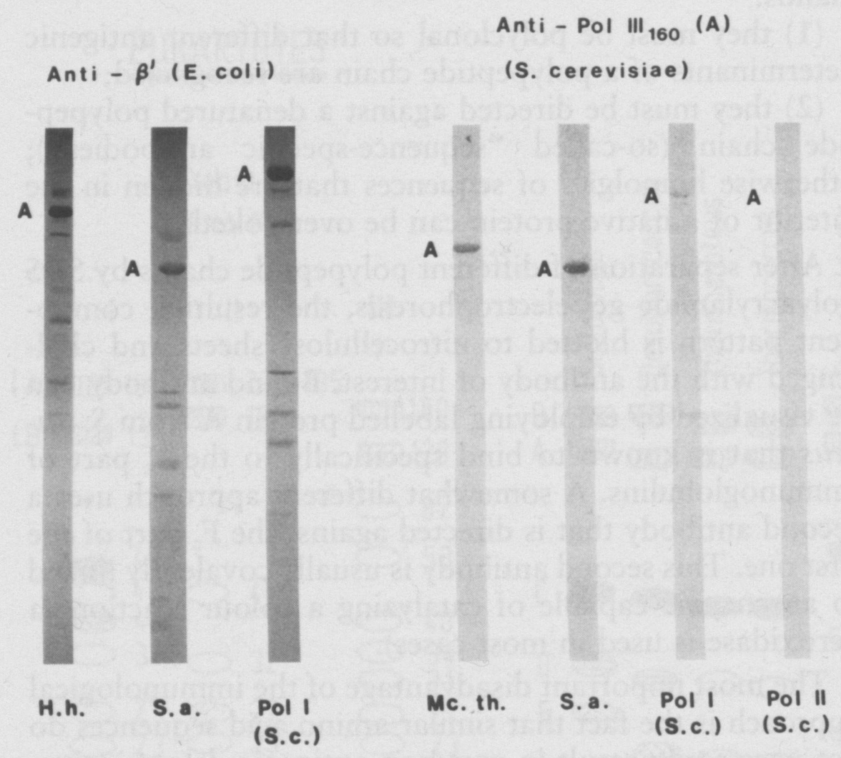

Fig. 2: The homology group of "A" subunits.

After separation of components of different RNA polymerases by SDS polyacrylamide gel electrophoresis and transfer to nitrocellulose sheets, homologous subunits were detected by incubation with the antibodies indicated. Bound immunoglobulin was visualized using peroxidase-coupled anti-antibody.

Abbreviations used:

H. h.: Halobacterium halobium

S. a.: Sulfolobus acidocaldarius

Mc. th.: Methanococcus thermolithotrophicus

S. c.: Saccharomyces cerevisiae archaebacterial A components whereas the immunological crossreaction with the largest component of yeast polymerase I is weak and such a reaction is barely detectable with the A subunit of polymerase II (Fig. 2). Since antibodies directed against the largest components of eukaryotic RNA polymerases I and II strongly crossreact with the A component of the archaebacterial enzymes one must conclude that all A components of the eukaryotic RNA polymerases are homologous though direct crossreaction cannot always be demonstrated.

(2) Antibodies directed against subunit $\beta^{\prime}$ of E. coli RNA polymerase crossreact with the A component of the archaebacterial enzymes and with the A component of yeast RNA polymerase I (Fig. 2). This crossreaction is strongest with the enzyme from $H$. halobium suggesting that the archaebacteria belonging to the halophilicl methanogenic branch are more closely related to eubacteria than the sulfur-dependent archaebacteria.

\section{The "B" components of DNA-dependent RNA polymerases}

Immunological crossreactions show the following components to be homologous:

- The second largest subunits of the three eukaryotic RNA polymerases (i.e. the "B" subunits)

- The largest component (B) of the RNA polymerases of sulfur-dependent archaebacteria

- The second largest $\left(\mathrm{B}^{\prime}\right)$ and the third largest $\left(\mathrm{B}^{\prime \prime}\right)$ component of the RNA polymerases of halophilic and methanogenic archaebacteria. $\mathrm{B}^{\prime}$ and $\mathrm{B}^{\prime \prime}$ within one RNA polymerase are immunologically unrelated, but both components crossreact with the B subunit of the RNA polymerases of sulfur-dependent archaebacteria.

- Subunit $\beta$ of eubacterial RNA polymerases

When antibodies directed against the second largest subunit (subunit B) of eukaryotic RNA polymerases are used, a strong crossreaction with component B of Sulfolobus RNA polymerase is observed (Fig. 4). Similar to the situation with the A components, crossreactions between the B subunits of the three eukaryotic RNA polymerases themselves are mostly rather weak or not detectable at all whereas the crossreaction with the corresponding Sulfolobus component can easily be demonstrated.

Antibodies against component B of Sulfolobus RNA polymerase crossreact with two components of the enzymes from halophilic and methanogenic archaebacteria, that have therefore been termed $\mathrm{B}^{\prime}$ and $\mathrm{B}^{\prime \prime}$ (Fig. 3). Antibodies directed against $\mathrm{B}^{\prime}$ and $\mathrm{B}^{\prime}$ from Methanobacterium thermoautotrophicum both strongly crossreact with component B of Sulfolobus RNA polymerase, but no crossreaction is observed between the components $\mathrm{B}^{\prime}$ and $\mathrm{B}^{\prime \prime}$ themselves. This strongly suggests that $\mathrm{B}^{\prime}$ and $\mathrm{B}^{\prime \prime}$ can be viewed as fragments of a larger B component. Since the sizes of $\mathrm{B}^{\prime}$ and $\mathrm{B}^{\prime \prime}$ of different RNA polymerases vary to some degree (in Methanolobus $\mathrm{B}^{\prime \prime}$ is even somewhat larger than $\mathrm{B}^{\prime}$ ) the question arises whether the split of the large B subunit is in the same position in RNA polymerases from different halophilic and methanogenic archaebacteria. Experimental data show that the distribu- 
Anti - B

(S. acidocaldarius)

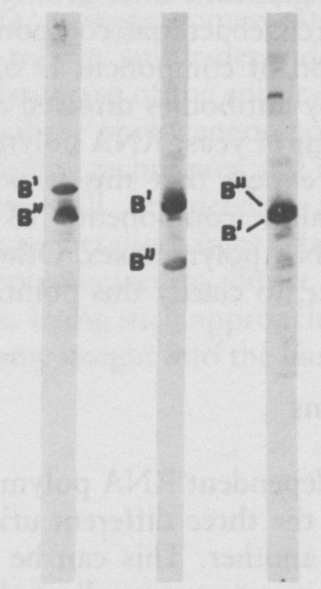

H.h.

Mc.th. MI.v.
Anti - B'

(Mb. thermoautotrophicum)

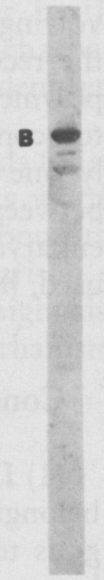

s.a.

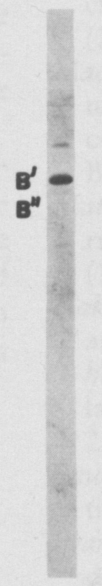

H.h.

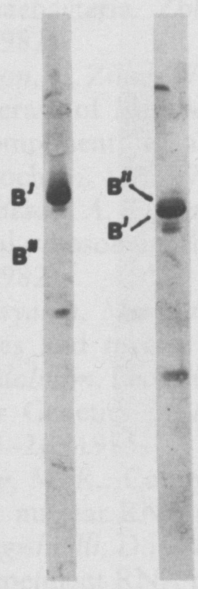

Mc.th.
Anti - B"

(Mb. thermoautotrophicum)

Fig. 3: The homology group of "B" components of archaebacteria. For details of the method used to detect homologies see Fig. 2. Abbrevations used: Mc. th.: Methanococcus thermolithotrophicus

H. h.: Halobacterium halobium Ml.v.: Methanolobus vulcanii

S. a.: Sulfolobus acidocaldarius

Anti - $\beta$ (E.coli)

Anti - Pol III 128 (B)

B

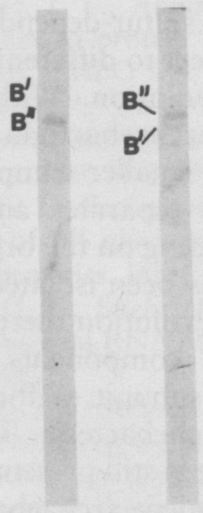

s. a.

H.h. (s.

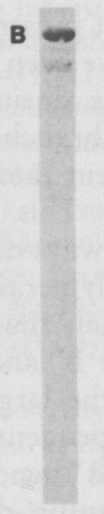

S.a.

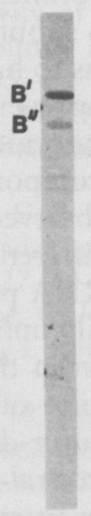

H.h.

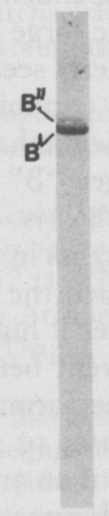

MI.v.

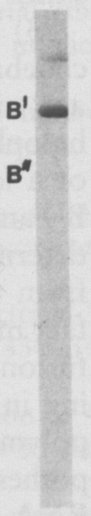

Mc.th.

Fig. 4: "B" component homology group of RNA polymerases from archaebacteria, eubacteria and eukaryotes.

For details of the method used to detect homologies see Fig. 2. Abbrevations used:

S. a.: Sulfolobus acidocaldarius

H. h.: Halobacterium halobium

Ml.v.: Methanolobus vulcanii

Mc. th.: Methanococcus thermolithotrophicus

tion of antigenic determinants to $\mathrm{B}^{\prime}$ and $\mathrm{B}^{\prime \prime}$ is not identical in different enzymes of this type. Thus antibodies directed against $\mathrm{B}^{\prime}$ of $\mathrm{Mb}$. thermoautotrophicum crossreact with the $\mathrm{B}^{\prime}$ subunits of $M c$. thermolithotrophicus, $M l$. vulcanii and $H$. halobium exclusively. Antibodies directed against $\mathrm{B}^{\prime \prime}$ of $M b$. thermoautotrophicum, however, show a crossreaction with $\mathrm{B}^{\prime}$ of $H$. halobium and $M l$. vulcanii though the reaction is weaker than that with

$\mathrm{B}^{\prime \prime}$. In the case of $M c$. thermolithotrophicus only $\mathrm{B}^{\prime \prime}$ crossreacts, indicating that antigenic determinants have been separated in the same ways in Methanobacterium and Methanococcus (Fig. 3).

Antibodies directed against subunit $\beta$ of $E$. coli RNA polymerase crossreact weakly yet significantly with the B components of Sulfolobus RNA polymerase and yeast polymerase II (Fig.4). As far as the enzymes from halophilic and methanogenic archaebacteria are concerned, anti- $\beta$ shows the same pattern of crossreactions that is observed with antibodies directed against component $B^{\prime \prime}$ of $M b$. thermoautotrophicum (Fig. 3 and 4). The $\mathrm{B}^{\prime \prime}$ components of all enzymes of this branch are recognized by anit- $\beta$. In addition there is also a weaker crossreaction of anti- $\beta$ with $\mathrm{B}^{\prime}$ of Halobacterium and Methanolobus. B' of Methanococcus, however, does not react.

On the other hand antibodies directed against the B subunits of eukaryotic RNA polymerases show a pattern of crossreactions with enzymes from halophilic and methanogenic archaebacteria that is very similar to that obtained using antibodies against component $\mathrm{B}^{\prime}$ of $\mathrm{Mb}$. thermoautotrophicum (Fig. 3 and 4). Strong crossreaction is observed with $\mathrm{B}^{\prime}$ but not $\mathrm{B}^{\prime \prime}$ of these enzymes. One exception is a weak crossreaction of anti- $\mathrm{III}_{128}$ with $H$. halobium $\mathrm{B}^{\prime \prime}$ though the reaction with $\mathrm{B}^{\prime}$ is much stronger.

\section{Homologies between smaller components}

With decreasing length of polypeptide chains there is an increasing probability that existing homologies between two proteins cannot be demonstrated any more by the immunochemical approach. Within the urkingdom of archaebacteria, it is possible to identify the " $\mathrm{C}$ " components 


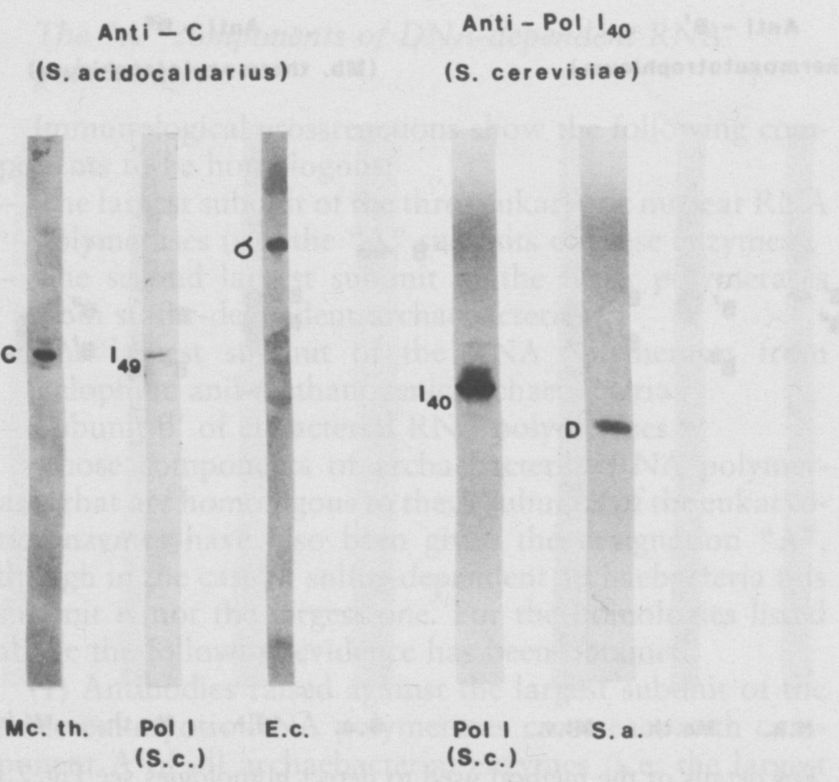

Fig. 5: Immunological crossreactions between smaller components of RNA polymerases from archaebacteria, eubacteria and eukaryotes.

For details of the method used to detect homologies see Fig. 2. Abbrevations used:

S. c.: Saccharomyces cerevisiae

S. a.: Sulfolobus acidocaldarius

Mc. th.: Methanococcus thermolithotrophicus

E. c.: Escherichia coli

of all RNA polymerases using antibodies directed against component $\mathrm{C}$ of the Sulfolobus enzyme.

Employing antibodies raised against components D and E of Sulfolobus RNA polymerase, homologous components of other archaebacterial RNA polymerases could only be identified in some cases. Occasionally it is possible to observe immunological crossreactions between smaller components of RNA polymerases, even when the enzymes belong to organisms from different urkingdoms.

Antibodies directed against component C of Sulfolobus RNA polymerase crossreact with the $\sigma$ factor of $E$. coli as well as with the 49 kilodalton component of yeast RNA polymerase I (Fig. 6). By using antibodies against E. coli $\sigma$ and $S$. cerevisiae $\mathrm{I}_{49}$, however, a crossreaction with Sul-

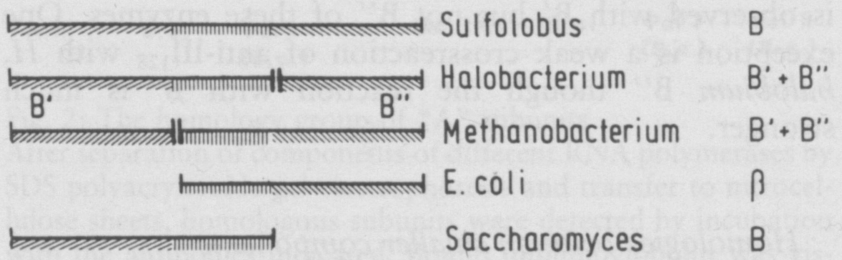

Fig. 6: Schematic drawing of the distribution of conserved antigenic determinants in the component "B" homology group of DNA-dependent RNA polymerases.

Corresponding antigenic determinants are indicated by equal hatching. folobus $\mathrm{C}$ is at the limit of detection (using anti- $\sigma$ ) or cannot be observed at all (using anti- $\mathrm{I}_{49}$ ).

The only significant inter-urkingdom crossreaction involving an archaebacterial component smaller than $\mathrm{C}$ is the recognition of component D of the Sulfolobus RNA polymerase by antibodies directed against the 40 kilodalton component of yeast RNA polymerase I (Fig. 6). Clearly one must expect that this is not the only homology between smaller components of archaebacterial and eukaryotic RNA polymerases. Other methods have to be used, however, to clarify this point.

\section{Conclusions}

(1) DNA-dependent RNA polymerases from organisms belonging to the three different urkingdoms are homologous to one another. This can be clearly shown for the largest subunits present in all of these enzymes and it is probably also true for some of the smaller components.

(2) The largest subunits of the three different eukaryotic nuclear RNA polymerases are more related to the corresponding components of the enzymes from archaebacteria than to one another. This strongly suggests that these three eukaryotic RNA polymerases have evolved from an ancestral enzyme that was very similar to the RNA polymerase as it is found today in archaebacteria, especially the sulfur-dependent branch.

(3) The large B subunit present in sulfur-dependent archaebacteria seems to have been subject to different cleavage and trimming events during evolution. Within the halophilic/methanogenic branch of archaebacteria a split of a larger " $\mathrm{B}$ " component into the smaller components $\mathrm{B}^{\prime}$ and $\mathrm{B}^{\prime \prime}$ is observed. This split separates antigenic determinants in different ways depending on the organism from which the RNA polymerase has been isolated. This fact makes it highly unlikely that in evolution there was a fusion event between the $\mathrm{B}^{\prime}$ and $\mathrm{B}^{\prime \prime}$ components resulting in the formation of the large B subunit of the RNA polymerases of sulfur-dependent arachebacteria. The hypothesis of an ancestral " $\mathrm{B}$ " gene that is still present in the RNA polymerases from sulfur-dependent archaebacteria, but has been split into two different components in RNA polymerases from halophilic and methanogenic archaebacteria, appears much more attractive. The investigation of the organization of the genes coding for $\mathrm{B}^{\prime}$ and $\mathrm{B}^{\prime \prime}$ in halophilic and methanogenic archaebacteria is the obvious approach to obtain more detailed information. Whereas in all archaebacteria the whole ancestral " $B$ " gene appears to be present (whether split or not), in eubacteria and eukaryotes obviously only part of it has been conserved. Experimental data indicate that a part chiefly corresponding to the $\mathrm{B}^{\prime \prime}$ component of halophilic and methanogenic archaebacteria has been conserved in the $\beta$ subunit of eubacteria whereas another, somewhat overlapping part of the putative ancestral " $\mathrm{B}$ " gene (mainly corresponding to $\mathrm{B}^{\prime}$ in halophilic and methanogenic archaebacteria is found in the B subunits of RNA polymerases of eukaryotes (Fig. 5). Since the $\beta$ subunit of E. coli RNA polymerase is believed to harbour the catalytic sites 
for the polymerization reaction, these findings are of special interest.

(4) Thermoplasma acidophilum, which on the basis of rRNA sequence data appears somewhat closer to the methanogenic than to the sulfur-dependent archaebacteria, has a RNA polymerase of the sulfur-dependent type indicating an intermediate phylogenetic position.

Since molecular cloning techniques and methods for sequencing of DNA are well advanced, it appears worthwhile to obtain more detailed information about the evolution of RNA polymerases by direct comparison of amino acid sequences. Using such approaches it might also be possible to gain some insight into the basic mechanisms of transcription.

\section{References}

Bubler, J. M., Huet, J., Davies, K. E., Sentenac, A., Fromageot, $P .:$ Immunological studies of yeast nuclear RNA polymerases at the subunit level. J. Biol. Chem. 255, 9949-9954 (1980)

Burgess, R. R.: Purification and Physical Properties of E. coli RNA Polymerase. In: RNA Polymerase, P. Losick and $M$. Chamberlin, eds., pp. 69-100. Cold Spring Harbor/New York, Cold Spring Harbor Laboratory 1976

Cammarano, P., Teichner, A., Londei, P., Acca, M., Nicolaus, B., Sanz, J. L., Amils, R.: Insensitivity of archaebacterial ribosomes to protein synthesis inhibitors. Evolutionary implications. EMBO J. 4, 811-816 (1985)

Forterre, P., Elie, C., Kohiyama, M.: Amphidicolin inhibits growth and DNA synthesis in halophilic archaebacteria. J. Bact. 159, 800-802 (1984)

Fox, G. E., Pechmann, K.J., Woese, C. R.: Comparative cataloging of $16 \mathrm{~S}$ ribosomal RNA: molecular approach to procaryotic systematics. Int. J. system. Bact. 27, 44-57 (1977)

Fox, G. E., Luehrsen, K. R., Woese, C. R.: Archaebacterial $5 S$ ribosomal RNA. Zbl. Bakt. Hyg., I. Abt. Orig. C 3, 330-345 (1982)

Gupta, R.: Halobacterium volcanii tRNAs: Identification of 41 tRNAs covering all amino acids, and the sequences of 33 class I tRNAs. J. Biol. Chem. 259, 9461-9471 (1984)

Herzfeld, F., Kiper, M.: The reconstitution of Anacystis nidulans DNA-dependent RNA polymerase from its isolated subunits. Europ. J. Biochem. 62, 189-192 (1976)

Huet, J., Schnabel, R., Sentenac, A., Zillig, W.: Archaebacteria and eukaryotes possess DNA-dependent RNA polymerases of a common type. EMBO J. 2,1291-1294 (1983)

Kandler, O.: Cell wall structures and their phylogenetic implications. Zbl. Bakt. Hyg., I. Abt. Orig. C 3, 149-160 (1982)

Kessel, M., Klink, F.: Identification and comparison of eighteen archaebacteria by means of the diphtheria toxin reaction. $\mathrm{Zbl}$. Bakt. Hyg., I. Abt. Orig. C 3, 140-148 (1982)

Klimczak, L. J., Grummt, I., Burger, K. J.: Archaebacterial DNA polymerases. Lecture given at the "EMBO Workshop on
Molecular Genetics of Archaebacteria”, held in Martinsried, June 23-26 (1985)

Langworthy, T. A., Tornabene, T. G., Holzer, G.: Lipids of archaebacteria. Zbl. Bakt. Hyg., I. Abt. Orig. C 3, 228-244 (1982)

Madon, J., Zillig, W.: A form of the DNA-dependent RNA polymerase of Halobacterium halobium containing an additional component, is able to transcribe native DNA. Europ. J. Biochem. 133, 471-474 (1983)

Matheson, A. T., Yaguchi, M.: The evolution of the archaebacterial ribosome. Zbl. Bakt. Hyg., I. Abt. Orig. C 3, 192-199 (1982)

Nakayama, M., Mabrez, K. B., Kohiyama, M.: DNA polymerases and reverse transcriptase-primase from Halobacterium halobium. Lecture given at the "EMBO Workshop on Molecular Genetics of Archaebacteria", held in Martinsried, June 23-26 (1985)

Paule, M. R.: Comparative subunit composition of the eukaryotic nuclear RNA polymerases. TIBS May 1981, 128-131

Prangishvilli, D., Zillig, W., Gierl, A., Biesert, L., Holz, I.: DNAdependent RNA polymerases of thermoacidophilic archaebacteria. Europ. J. Biochem. 122, 471-477 (1982)

Prangishvilli, D., Zillig, W.: DNA-dependent DNA polymerases of the thermoacidophilic archaebacterium Sulfolobus acidocaldarius. Poster presented at the FEMS symposium "Evolution of Prokaryotes", held in Munich, September 16-18 (1984)

Schnabel, R., Thomm, M., Gerardy-Schahn, R., Zillig, W., Stetter, K. O., Huet, J.: Structural homology between different archaebacterial DNA-dependent RNA polymerases analyzed by immunological comparison of their components. EMBO J. 2, 751-755 (1983)

Thomm, M., Stetter, K. O.: Transcription in methanogens: evidence for specific in vitro transcription of the purified DNAdependent RNA polymerase of Methanococcus thermolithotrophicus. Europ. J. Biochem. 149, 345-351 (1985)

Woese, C. R., Fox, G. E.: Phylogenetic structure of the prokaryotic domain: The primary kingdoms. Proc. nat. Acad. Sci. (Wash.) 74, 5088-5090 (1977)

Woese, C. R., Magrum, L. J., Fox, G. E.: Archaebacteria. J. Molec. Evol. 11, 245-252 (1978)

Yaguchi, M., Visentin, L. P., Zuker, M., Matheson A. T., Roy, C., Strom A. R.: Amino-terminal sequences of ribosomal proteins from the $30 S$ subunit of archaebacterium Halobacterium cutirubrum. Zbl. Bakt. Hyg., I. Abt. Orig. C 3, 200-208 (1982)

Zillig, W., Palm, P., Heil, A.: Function and Reassembly of Subunits of DNA-dependent RNA Polymerase. In: RNA Polymerase, R. Losick and M. Chamberlin, eds., pp. 101-125. Cold Spring Harbor/New York, Cold Spring Harbor Laboratory 1976

Zillig, W., Stetter, K. O., Tobien, M.: DNA-dependent RNA polymerase from Halobacterium halobium. Europ. J. Biochem. 91, 193-199 (1978)

Zillig, W., Stetter, K. O., Janekovic, D.: DNA-dependent RNA polymerase from the archaebacterium Sulfolobus acidocaldarius. Europ. J. Biochem. 96, 597-604 (1979)

Zillig, W., Stetter, K. O., Schnabel, R., Madon, J., Gierl., A.: Transcription in archaebacteria. Zbl. Bakt. Hyg., I. Abt. Orig. C 3, 218-227 (1982) 


\title{
Transfer RNAs of Halobacterium volcanii: Sequences of Five Leucine and Three Serine tRNAs*
}

\author{
RAMESH GUPTA
}

Department of Medical Biochemistry, and Department of Chemistry and Biochemistry, Southern Illinois University, Carbondale, IL 62901, U.S.A.

\begin{abstract}
Summary
The sequences of eight class II transfer RNAs (those having the large extra arm) of Halobacterium volcanii, five for leucine and three for serine are presented here. In principle, these tRNAs cover at least 11 out of the possible 12 codons for these two amino acids. Although these tRNAs follow general patterns for the class II tRNAs, in detail they are distinct from both eucaryotic and eubacterial tRNAs.
\end{abstract}

Key words: tRNA - Halobacterium volcanii - Archaebacteria - Extreme halophiles - RNA sequencing

\section{Introduction}

Transfer RNA plays a major role in protein biosynthesis and so this molecule has been extensively studied. Within the last 20 years, sequences of more than 350 tRNAs from various sources have been determined (Sprinzl et al., 1985). Though the sequences of these tRNAs differ significantly, nearly all fit the "cloverleaf" secondary structure (some mitochondrial tRNAs are the exceptions).

Within a cell, the tRNA molecule interacts with several macromolecules. In some of these interactions, different tRNAs associate with the same macromolecule, e.g., a ribosomal component, while in others, each tRNA (or one group of isoacceptors) interacts with a specific cognate member of a set of macromolecules, e.g., aminoacyltRNA synthetases. Therefore, in any tRNA molecule, there are some features which are common to all tRNAs, while there are other characteristics which are specific to that particular tRNA (or that particular group of isoaccep-

* Paper given at the EMBO Workshop on the Molecular Genetics of Archaebacteria, München-Martinsried, June 23 to 26, 1985.

\section{Abbreviations:}

$\mathrm{p}, 5^{\prime}$-phosphate. The modified residues are referred to as: $t^{6} \mathrm{~A}$, $\mathrm{N}$-[9- $\beta$-D-ribofuranosylpurin-6-yl)carbamoyl]threonine; $\mathrm{m}^{5} \mathrm{C}$, 5-methyl C; $\mathrm{ac}^{4} \mathrm{C}, \mathrm{N}^{4}$-acetyl C; $\mathrm{Cm}, 2^{\prime} \mathrm{O}$-methyl $\mathrm{C}$; $\mathrm{m}^{1} \mathrm{G}, 1$ methyl $G ; \mathrm{m}^{2} \mathrm{G}, \mathrm{N}^{2}$-methyl $\mathrm{G} ; \mathrm{m}_{2}^{2} \mathrm{G}, \mathrm{N}^{2}, \mathrm{~N}^{2}$-dimethyl $\mathrm{G}$; mo ${ }^{5} \mathrm{U}$, 5-methoxy $\mathrm{U} ; \mathrm{U}$, a specific unidentified modified $\mathrm{U} ; \psi$, pseudouridine; $\mathrm{m}^{1} \psi, 1$-methyl $\psi ; \mathrm{D}$, dihydrouridine; $\mathrm{T}$, ribothymidine; $\mathrm{m}^{1} \mathrm{I}$, 1-methyl Inosine; R, purine; Y, pyrimidine; X, a specific unidentified modified $\mathrm{G} ; \mathrm{N}$, any nucleoside. tors). Furthermore, a comparative study of tRNA sequences has suggested several eubacteria- and eukaryotespecific features both in the sequences, as well as in the modification pattern of the tRNAs (Singhal and Falls, 1979; Gupta, 1985).

Among archaebacteria, the sequences of $37 \mathrm{tRNAs}$ from the extreme halophiles, 3 from the thermoacidophiles and 2 from the methanogens are so far reported (Kilpatrick and Walker, 1981; Kuchino et al., 1982; Gu et al., 1983, 1984; Gupta, 1984). These archaebacterial tRNAs show the general cloverleaf structure common to all tRNAs. However, they have several unique characteristics, and show similarity to the eubacterial tRNAs in some features, while to the eukaryotic tRNAs in other (Kuchino et al., 1982; Gupta, 1984, 1985). The same holds for the overall modification patterns of the archaebacterial tRNAs (Gupta and Woese, 1980). A detailed review of the archaebacterial tRNAs has recently been published (Gupta, 1985).

The sequences of five tRNAs for leucine and three tRNAs for serine, from an archaebacterium, Halobacterium volcanii, are presented here. These, along with the previously reported 33 tRNA sequences (Gupta, 1984) of $H$. volcanii can be compared with the available sets of tRNA sequences for eubacteria and eucaryotes (Sprinzl et al., 1985).

\section{Materials and Methods}

All the procedures for separation and sequencing of these tRNAs have been described previously (Gupta, 1984). 